\title{
A new approach to integrate PLZT thin films with micro-cantilevers
}

\author{
RAVINDRA SINGH ${ }^{\mathrm{a}, *}$, T C GOEL $^{\mathrm{b}}$ and SUDHIR CHANDRA ${ }^{\mathrm{a}}$ \\ ${ }^{a}$ Centre for Applied Research in Electronics, Indian Institute of Technology \\ Delhi, New Delhi 110016 \\ ${ }^{b}$ BITS Pilani Goa Campus, Zuari Nagar, Goa 403726 \\ e-mail: ravindrasingh76@yahoo.com
}

\begin{abstract}
In the present work, we report the preparation of PLZT thin films in pure perovskite phase by RF magnetron sputtering without external substrate heating and their integration with micro-cantilevers. The 'lift-off' process for patterning different layers of a micro-cantilever including PLZT, Pt/Ti and $\mathrm{Au} / \mathrm{Cr}$ was employed. The basic requirement of lift-off process is that the deposition temperature should not exceed $200^{\circ} \mathrm{C}$ otherwise photoresist will burn out. Therefore, one of the aims of the present work was to prepare PLZT film at lower deposition temperatures, which can be subsequently annealed to form pure perovskite phase. This also strongly favours the incorporation of 'lift-off' process for patterning in the complete process flow. As no external substrate heating was required in the deposition of PLZT film, this objective has been successfully accomplished in the present work. The 'lift-off' process has been successfully adopted for patterning the composite layers of $\mathrm{PLZT} / \mathrm{Pt} / \mathrm{Ti}$ and $\mathrm{Au} / \mathrm{Cr}$ using thick positive photo-resist (STR-1045). Different types of cantilever beams incorporating PLZT films have been successfully fabricated using 'lift-off' process and bulk micromachining technology. The proposed process can be advantageously applied for the fabrication of various MEMS devices.
\end{abstract}

Keywords. PLZT thin films; pure perovskite phase; RF sputtering; lift-off process; micro-cantilevers.

\section{Introduction}

During recent years, ferroelectric lead zirconate titanate (PZT) and lanthanum modified PZT (PLZT) thin films have attracted much attention for microelectromechanical systems (MEMS) devices such as micro-sensors, micro-actuators, accelerometers, bulk acoustic resonators, surface acoustic wave (SAW) devices, chemical sensors etc. (Muralt 2000; Zinck et al 2004; Yan et al 2004; Zhang et al 2003). More recently, these films have shown great potential for micro-biosensors that also use the technology of MEMS (Lee et al 2004; Johnson et al 2006). These films are required to be prepared in pure perovskite phase for their best ferroelectric

*For correspondence 
(piezoelectric) response. The high resistivity of the films is a pre-requisite for devices based on piezoelectric properties. Furthermore, the film deposition at comparatively low temperature is of great interest for realization of MEMS structures. Amongst the various methods, solgel and sputtering are the most attractive techniques for preparing these films. The solgel technique has the advantage that the composition of the film can be easily tailored for optimum performance (Weng et al 2002). Also, the pure perovskite phase is easy to obtain using this technique. However, this technique is cumbersome and quite difficult to integrate with the fabrication technology of microelectronic devices. On the other hand, the sputtering technique is a well-established and accepted process in IC and MEMS fabrication (Wang \& He 2005). Furthermore, sputtering process also yields more reproducible and stable film properties. Another important advantage of sputtering is that it is a low temperature process (Park et al 2005). However, the pure perovskite phase formation using sputtering is a difficult task and it requires precise control of all deposition parameters. In the present work, PLZT thin films were prepared in pure perovskite phase by RF magnetron sputtering. The structural and electrical properties of the films have been investigated.

Apart from the preparation of the PLZT films with desired structure and properties, their integration with MEMS is much more challenging task. Recently, an extensive research has been carried out to integrate these films with MEMS (Filhol et al 2005; Hong et al 2005; Lee et al 2005) and the further improvements are still going on. The fabrication process of MEMS structures (e.g. micro-cantilevers) incorporating piezoelectric film requires the patterning of all the composite layers of the cantilever including PLZT, electrode materials and structural layers which is usually done by etching process. Platinum is considered to be best material for the lower electrode for these films (Thomas et al 2001). The selective etching of the layers of different materials is very difficult using wet chemical etchants. The etchant of a particular layer material could attack the other layers and damage the whole process. For this purpose, researchers generally use dry etching techniques such as reactive ion etching (RIE), ion beam etching (IBE), inductively coupled plasma (ICP) etching and ion milling process (Baborowski et al 2000; Ferguson et al 2005). These require dedicated and expensive infrastructure. In the present work, we propose 'lift-off' process for patterning platinum as well as PLZT film that enables the use of conventional wet anisotropic etching techniques to integrate these films in MEMS fabrication process.

\section{Experimental work}

\subsection{Preparation of PLZT thin films}

Thin films of PLZT were prepared on $\mathrm{Pt} / \mathrm{Ti} / \mathrm{SiO}_{2} / \mathrm{Si}$ substrates of 2 -inch diameter by $\mathrm{RF}$ magnetron sputtering. For this purpose, a 3-inch diameter PLZT (8/60/40) target was prepared in-house by conventional solid-state reaction route. The preparation method of the target has been reported earlier (Singh et al 2005). The 8/60/40 composition of the target was selected on the basis of our previous study on sol-gel prepared PLZT films (Singh et al 2004). Both the $\mathrm{Ti}(30 \mathrm{~nm})$ and $\mathrm{Pt}(150 \mathrm{~nm})$ films were prepared by planar RF sputtering at 10 mtorr pressure in the same sputtering system. The $\mathrm{SiO}_{2}(1 \mu \mathrm{m}$ thickness $)$ was grown by wet oxidation process at $1150^{\circ} \mathrm{C}$. In order to optimize target-to-substrate spacing, deposition temperature, post-deposition annealing temperature and time for obtaining pure perovskite phase of PLZT, a number of films were prepared under different deposition conditions. The chamber was evacuated to $1 \times 10^{-5}$ torr pressure before introducing the sputtering gas. Sputtering of PLZT was carried out in argon by supplying 100 watt RF power at a frequency of $13.56 \mathrm{MHz}$. 
The sputtering pressure was maintained at 5 mtorr for all the depositions. No external heating was provided to the substrate during the sputtering process. To exploit the self-heating phenomena of the substrate in plasma during sputtering process (Maissel \& Glang 1970), the substrate holder was designed to minimize the heat loss to the chamber. This enabled the substrate temperature to rise during sputtering process even when no external heating was used. Optimization of target-substrate spacing was carried out to prepare a uniform PLZT film with smooth surface texture. The deposition rate and the thickness-uniformity were found to be good at $50 \mathrm{~mm}$ target-substrate spacing. Therefore, we selected $50 \mathrm{~mm}$ target-substrate spacing to prepare the PLZT films for the present study. As the PLZT films were deposited at comparatively low temperatures (self-heating temperature reached upto $155^{\circ} \mathrm{C}$ ), the films were formed in amorphous phase, as confirmed by XRD. Therefore, the films were subsequently subjected to furnace annealing as well as rapid thermal annealing (RTA) to obtain the perovskite phase.

\subsection{Characterization of the films}

In order to investigate the structural/crystallographic properties of PLZT films, X-ray diffraction (XRD) analysis was carried out on PW 3040 Philips X'Pert X-ray diffractometer using $\mathrm{CuK} \alpha(\lambda=1.5405 \AA)$ radiation. The thickness of the films was determined using surface profiler (Tencor Instruments) and kept $0.6 \mu \mathrm{m}$ for all the depositions. The step was formed by lithography and etching of the films. The PLZT films were etched in 5\% HF solution. For the measurement of leakage current of the films, top electrodes of chrome-gold $(\mathrm{Cr}-\mathrm{Au})$ of area $0.44 \mathrm{~mm}^{2}$ were formed by RF sputtering followed by lithography. The other contact was taken laterally from platinum underneath the PLZT film. The leakage current was measured using a computer interfaced Keithley 2410, source meter.

\subsection{Fabrication of cantilever beams incorporating PLZT thin films}

To integrate PLZT thin films with micro-cantilevers, we propose lift-off technique for patterning the different layers of the cantilever beam. The basic requirement of 'lift-off' process is that the deposition temperature should not exceed $200^{\circ} \mathrm{C}$ otherwise photoresist will burn out (Sze 1988). As mentioned in the introduction, it was one of the goals of the present work to prepare PLZT films at lower deposition temperatures. This also suits the incorporation of 'lift-off' process for patterning in the complete process flow. As no external substrate heating was required in the deposition of PLZT films, this objective has been successfully accomplished. Another requirement for the 'lift-off' process is the choice of appropriate photoresist. The viscosity of photoresist should be high for producing thick layer using spin coating. This enables poor step-coverage during film deposition, which is a necessary condition for the success of the 'lift-off' process. After the deposition of films, the samples are put in stripping solution for 'lift-off' process. In addition, the stripping solution of photoresist should not attack the other layers. For this purpose, we have chosen a high- viscosity positive photoresist (Shipley, STR-1045). It gives $5 \mu \mathrm{m}$ thickness in a single coating at $3000 \mathrm{rpm}$ and acetone is used for photoresist stripping, which does not attack PLZT film. The 'lift-off' process has been successfully applied for patterning the composite layers of PLZT/Pt/Ti and Au/Cr using thick positive photo-resist (STR-1045).

Different types of cantilever beams incorporating PLZT films have been successfully fabricated using 'lift-off' process and anisotropic etching of silicon in EDP. For this purpose, the proposed structure of a cantilever beam is schematically shown in figure 1 . The cantilever consists of a structural layer of $\mathrm{SiO}_{2}$ and PLZT thin film sandwiched between $\mathrm{Pt} / \mathrm{Ti}$ 


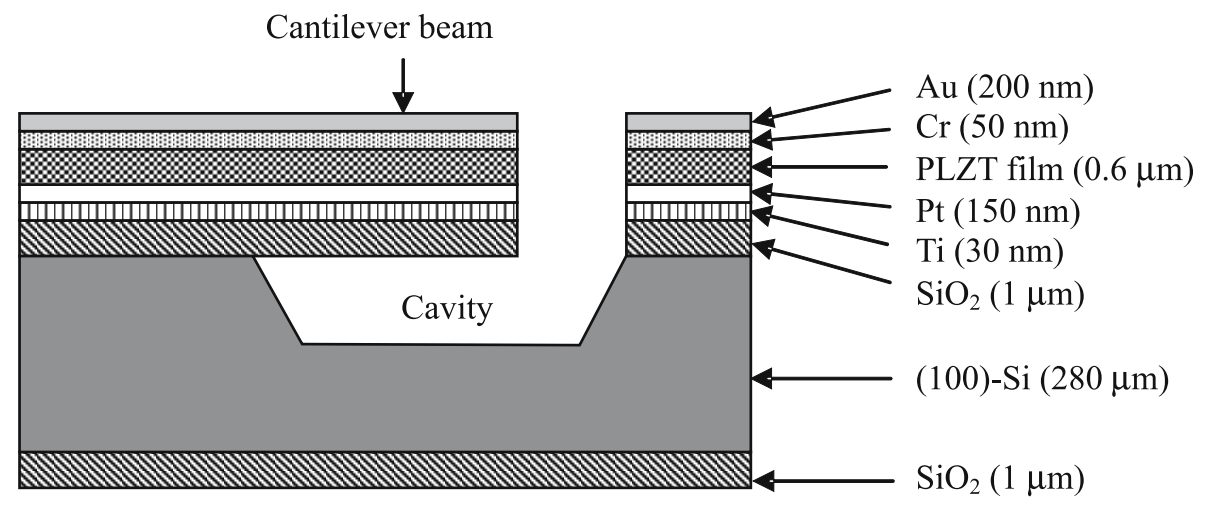

(a)

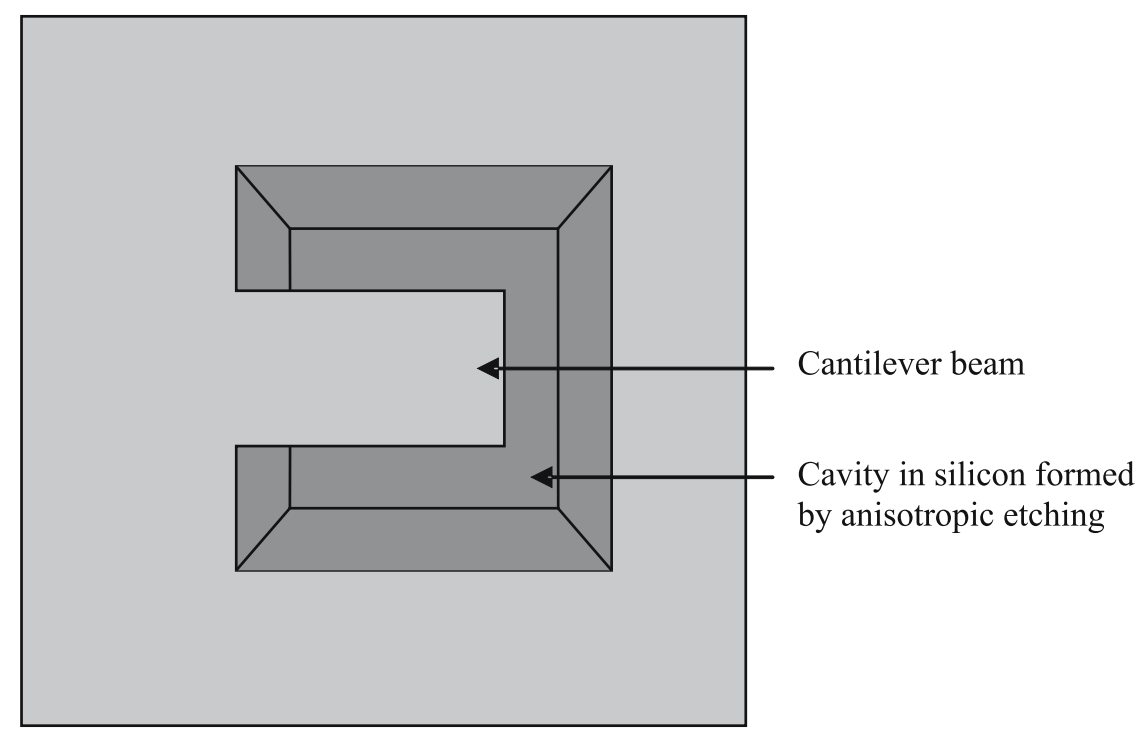

(b)

Figure 1. Schematic views of the proposed structure (cantilever beam) for demonstrating the integration of PLZT film: (a) cross-sectional view and (b) top view.

and $\mathrm{Au} / \mathrm{Cr}$ layers. The mask used for the fabrication process contained a number of cantilever structures of different shapes and dimensions. The complete process flow of the fabrication of a $\mathrm{Au} / \mathrm{Cr} / \mathrm{PLZT} / \mathrm{Pt} / \mathrm{Ti} / \mathrm{SiO}_{2}$ cantilever beam is shown in figure 2 . Initially, the 2-inch silicon wafers ( $p$-type $\langle 100\rangle, 280 \pm 20 \mu \mathrm{m}$ ) were wet oxidized at $1150^{\circ} \mathrm{C}$ to grow a $1 \mu \mathrm{m}$ thick oxide. For the lift off process, a thick positive photo-resist (STR-1045) was spin coated on the wafer. A pattern of cantilever structures from the emulsion mask plate was transferred to the photo-resist coated wafer using standard photolithography technique. Thereafter, the descum process is carried out. Then, the Ti $(30 \mathrm{~nm}), \mathrm{Pt}(150 \mathrm{~nm})$ and PLZT $(0.6 \mu \mathrm{m})$ were sequentially deposited on the patterned photo-resist coated wafer using optimized sputtering parameters. For the patterning of PLZT/Pt/Ti cantilever structures, the 'lift-off' process 


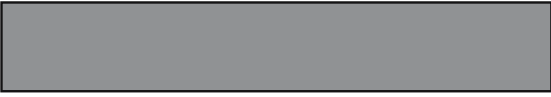

1. p-type $<100>, 280 \pm 20 \mu \mathrm{m}$ silicon wafer

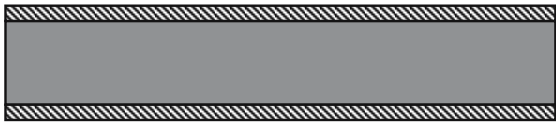

2. Wet thermal oxidation $(1 \mu \mathrm{m})$

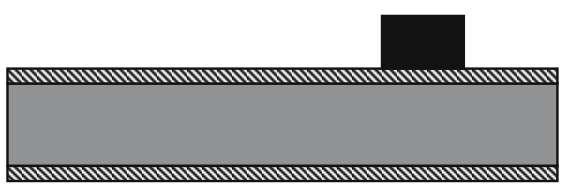

3. Coating and patterning of a thick positive photo-resist (STR-1050)

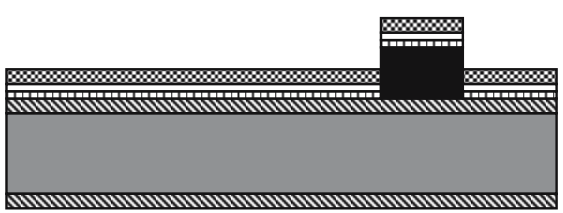

4. Deposition of Ti (30 nm), Pt (150 nm) and PLZT $(0.6 \mu \mathrm{m})$ by RF sputtering

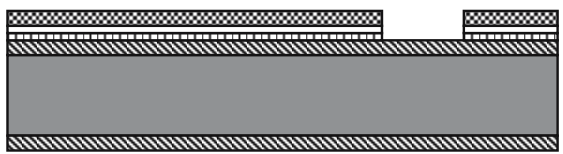

5. Lift off process carried out in acetone using ultrasonic bath and then furnace annealing of PLZT film at $650^{\circ} \mathrm{C}$ for 2 hrs in air ambient

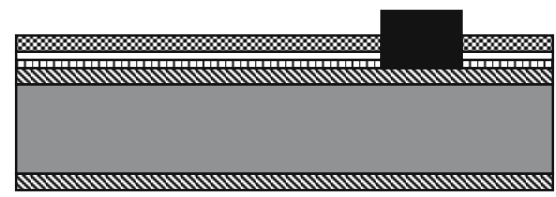

6. Coating and patterning of a thick positive photo-resist (STR-1045)

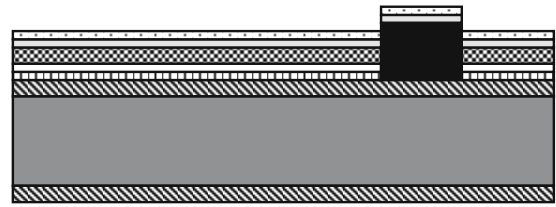

7. Deposition of $\mathrm{Cr}(50 \mathrm{~nm})$ and $\mathrm{Au}(200 \mathrm{~nm})$ by RF sputtering

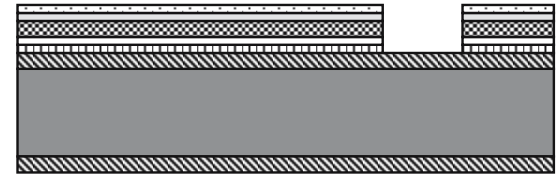

8. Lift off process carried out in acetone using ultrasonic bath

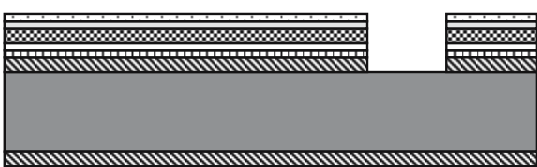

9. Reactive ion etching (RIE) of $\mathrm{SiO}_{2}$ in the mixture of $\mathrm{SF}_{6}$ and $\mathrm{CHF}_{3}$ gases

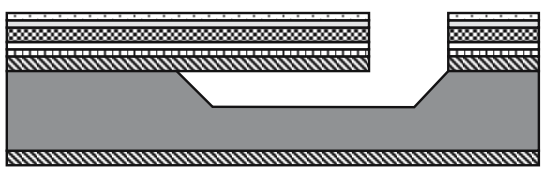

10. Anisotropic etching of silicon in EDP to release the cantilever beam

Figure 2. Process flow of the fabrication of cantilever beam of $\mathrm{Au} / \mathrm{Cr} / \mathrm{PLZT} / \mathrm{Pt} / \mathrm{Ti} / \mathrm{SiO}_{2}$.

was carried out in acetone using ultrasonic bath. After this step, the wafer was properly cleaned. The samples were then annealed at $650^{\circ} \mathrm{C}$ for $2 \mathrm{~h}$ in the furnace to form pure perovskite phase. The $\mathrm{Cr}(50 \mathrm{~nm})$ and $\mathrm{Au}(200 \mathrm{~nm})$ were then deposited by RF sputtering and patterned using the lift off process. The $\mathrm{SiO}_{2}$ from the window around cantilever structures was etched using reactive ion etching (RIE) in the mixture of $\mathrm{SF}_{6}$ and $\mathrm{CHF}_{3}$ gases. In the last step of fabrication, the silicon from the window was etched out using anisotropic etchant ethylene-diamine pyrocatechol (EDP) at $110^{\circ} \mathrm{C}$. Due to the under cutting of silicon at the convex corners, the cantilever beams were released after $1 \mathrm{hr}$ of etching in EDP. Finally, the 
wafer was carefully rinsed in de-ionized (DI) water followed by acetone and dried under IR lamp.

There are two main reasons of using EDP for anisotropic etching of silicon. First one is that EDP has very good selectivity between silicon and $\mathrm{SiO}_{2}$ compared to other etchant (e.g. $\mathrm{KOH}$ ). As we are using $\mathrm{SiO}_{2}$ as structural layer of cantilevers, therefore, it is necessary to use an etchant which has good selectivity between $\mathrm{Si}$ and $\mathrm{SiO}_{2}$. The second reason of using EDP is that it does not affect most of the metal layers (e.g. Au, Cr, etc.).

\section{Results and discussion}

\subsection{Structure and phase formation}

As mentioned in the introduction, preparation of PLZT thin films in pure perovskite phase by RF sputtering is a challenging task. This strongly depends on the various deposition parameters and post-deposition annealing treatment. The results for the effect of various deposition parameters such as sputtering gas composition, RF power, pressure, target-tosubstrate spacing, deposition temperature, post deposition annealing temperature and time on the phase formation of these films have been reported elsewhere (Singh et al 2008). The optimized deposition and post-deposition annealing parameters for the preparation of $0.6 \mu \mathrm{m}$ PLZT films in pure perovskite phase are given in table 1 . The films were prepared without external substrate heating in pure argon at 100 -watt RF power, $50 \mathrm{~mm}$ target-to-substrate spacing, and 5 mtorr sputtering pressure. The substrate temperature rises up to $155^{\circ} \mathrm{C}$ due to the plasma heating during sputtering process. The films exhibit pure perovskite phase after furnace annealing at $650^{\circ} \mathrm{C}$ for $2 \mathrm{~h}$ or rapid thermal annealing (RTA) at $700^{\circ} \mathrm{C}$ for $5 \mathrm{~min}$. The XRD patterns of the furnace and rapid thermal annealed pure perovskite PLZT films are shown in figure 3.

\subsection{Leakage current and DC resistivities}

High resistivity of these films is desired for device applications. Therefore, to determine the DC resistivity of these films, I-V measurements were carried out which are shown in figure 4. Low values of leakage current $\left(\sim 10^{-9} \mathrm{~A}\right)$ up to the field strength of $\sim 80 \mathrm{kV} / \mathrm{cm}$ were observed for furnace as well as rapid thermal annealed samples having pure perovskite

Table 1. Optimized deposition and post-deposition annealing parameters to prepare PLZT films in pure perovskite phase by RF magnetron sputtering.

\begin{tabular}{ll}
\hline Parameter & \multicolumn{1}{c}{ Conditions } \\
\hline RF power & 100 watt \\
Sputtering gas & Pure argon \\
Sputtering pressure & $5 \mathrm{mtorr}$ \\
Target-to-substrate distance & $50 \mathrm{~mm}$ \\
Deposition temperature & No external substrate heating (Temperature \\
& reaches around $155^{\circ} \mathrm{C}$ due to plasma heating) \\
Post-deposition annealing temperature and time & (i) Furnace annealing at $650^{\circ} \mathrm{C}$ for 2 hrs in air \\
& $\begin{array}{l}\text { ambient. } \\
\text { (ii) RTA at } 700^{\circ} \mathrm{C} \text { for } 5 \mathrm{~min} . \text { in } \mathrm{O}_{2} \text { ambient. }\end{array}$
\end{tabular}



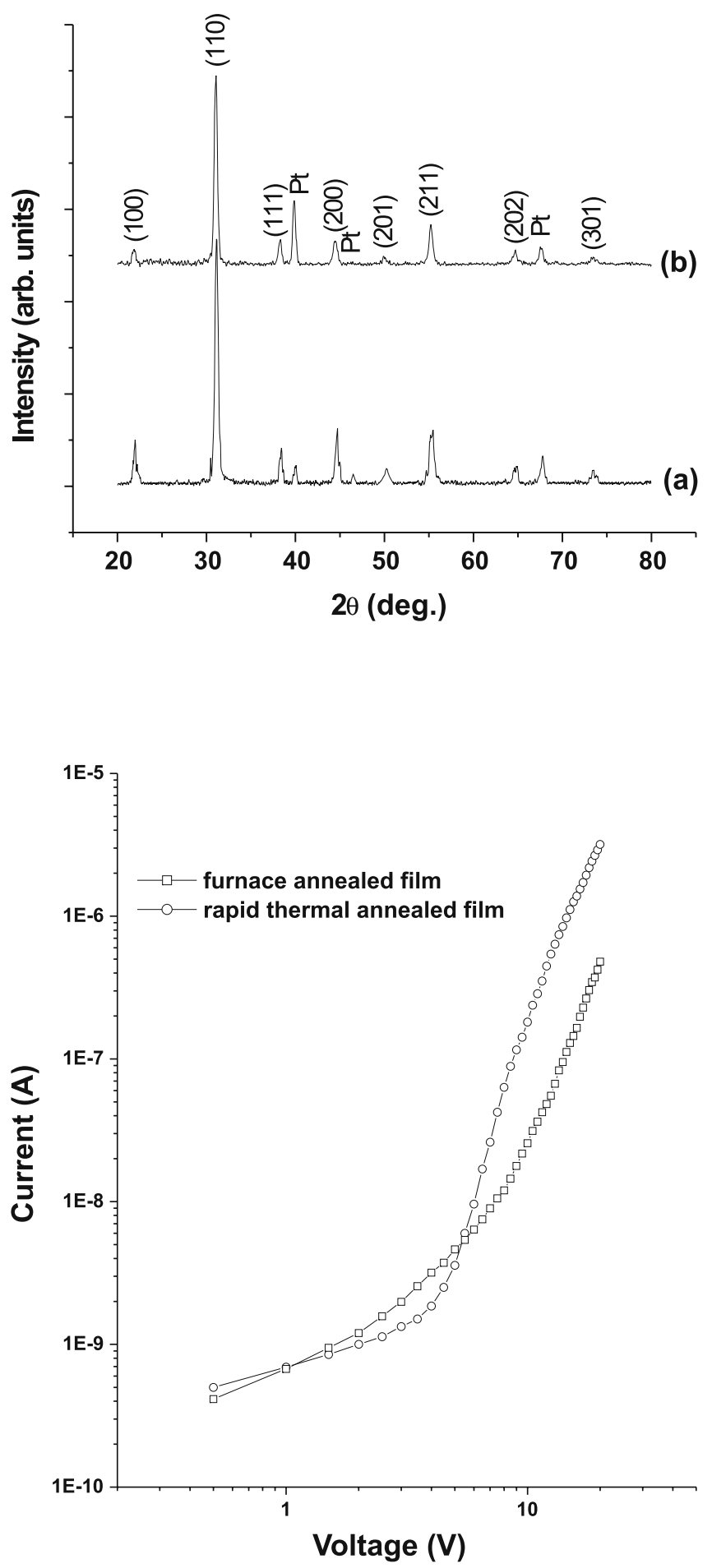

Figure 3. XRD patterns of (a) furnace and (b) rapid thermal annealed pure perovskite PLZT films.
Figure 4. I-V characteristics of pure perovskite PLZT thin films prepared under optimized deposition conditions. 


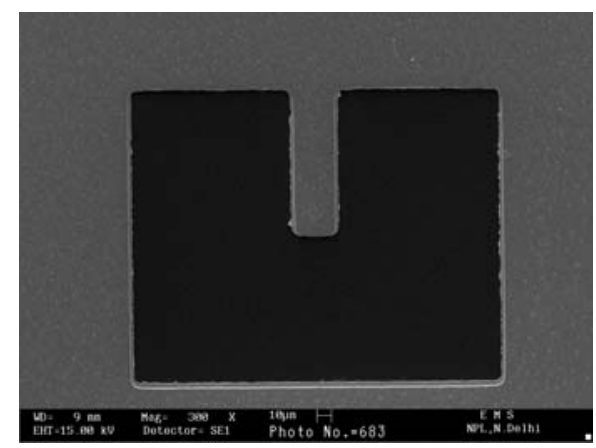

(a)

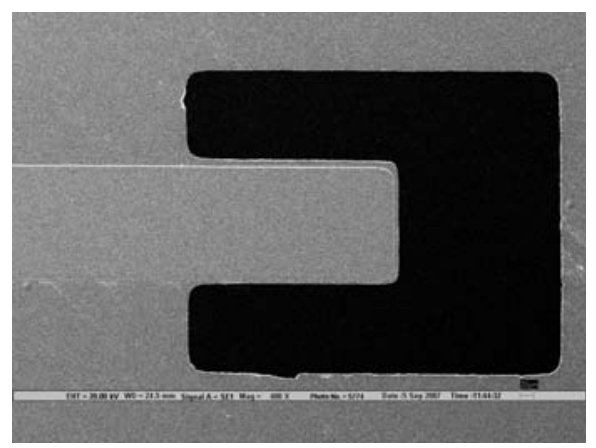

(b)

Figure 5. SEM photographs of cantilever structures patterned using lift-off process: (a) PLZT/Pt/Ti (thickness $\sim 0.77 \mu \mathrm{m}$ ) and (b) Au/Cr (thickness $\sim 0.2 \mu \mathrm{m}$ ) on PLZT/Pt/Ti (thickness $\sim 0.77 \mu \mathrm{m}$ ).

phase. From these measurements, the DC resistivities of the films were calculated and found to be $7.8 \times 10^{10}$ and $9.9 \times 10^{10} \Omega$-cm at the field strength of $\sim 80 \mathrm{kV} / \mathrm{cm}$ for the furnace and rapid thermal annealed pure perovskite films respectively. These values of the resistivities are reasonably good for the device applications.

\subsection{Cantilever beams}

Figure 5a shows the SEM photograph of cantilever shaped pattern of PLZT/Pt/Ti realized using 'lift-off' process. We have also applied the lift-off process to pattern the top $\mathrm{Au} / \mathrm{Cr}$ electrode using a different mask, which has slightly lower dimensions compared to that of the mask used to pattern the cantilever structures. The SEM photograph of this patterning is shown in figure $5 \mathrm{~b}$. It can be seen from these photographs that the composite layers of $\mathrm{PLZT} / \mathrm{Pt} / \mathrm{Ti}$ and $\mathrm{Au} / \mathrm{Cr}$ are well-patterned with fairly sharp edges. Therefore, it is worthy to say that the proposed 'lift-off' process can be applied to pattern the various thin film layers used to fabricate the MEMS devices.

The scanning electron micrographs of two types of $2.2 \mu \mathrm{m}$ thick cantilever beam of $\mathrm{Au} / \mathrm{Cr} / \mathrm{PLZT} / \mathrm{Pt} / \mathrm{Ti} / \mathrm{SiO}_{2}$ are shown in figure 6 . The micrographs reflect very fine patterning of the different layers and fully released cantilever beams. Although these cantilevers were fabricated using a single mask, the proposed process can be utilized for the fabrication
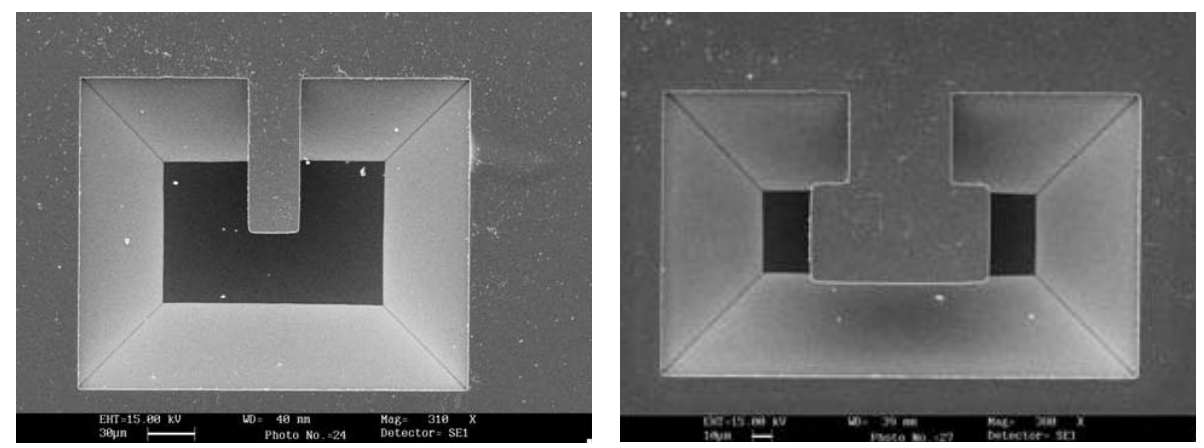

Figure 6. SEM of two types of $2.2 \mu \mathrm{m}$ thick cantilever beams of $\mathrm{Au} / \mathrm{Cr} / \mathrm{PLZT} / \mathrm{Pt} / \mathrm{Ti} / \mathrm{SiO}_{2}$. 
of complex microstructure using multiple masks. This process can be advantageously used to fabricate various MEMS devices such as micro-sensors, micro-actuators, accelerometers, bulk acoustic resonators, SAW devices, etc.

\section{Conclusions}

In this work, the deposition of PLZT thin films by RF magnetron sputtering and their integration with micro-cantilevers has been investigated. The various deposition and post-deposition annealing parameters were optimized to obtain pure perovskite phase of PLZT films. The PLZT films prepared without external substrate heating in pure argon at 100 watt RF power, $50 \mathrm{~mm}$ target-to-substrate spacing, 5 mtorr sputtering pressure exhibit pure perovskite phase after furnace annealing at $650^{\circ} \mathrm{C}$ for $2 \mathrm{~h}$ and rapid thermal annealing at $700^{\circ} \mathrm{C}$ for $5 \mathrm{~min}$. Both the pure perovskite films exhibit high DC resistivities of the order of $10^{11} \Omega$-cm at the electric field of $\sim 80 \mathrm{kV} / \mathrm{cm}$, which are good for their applications in devices.

The preparation of PLZT films without external substrate heating fulfills the basic requirement of low processing temperature for 'lift-off' process. The 'lift-off' process has been successfully applied for patterning the composite layers of PLZT/Pt/Ti and $\mathrm{Au} / \mathrm{Cr}$ using thick positive photo-resist. The compatibility of PLZT films with the fabrication process of microcantilevers has been demonstrated by fabricating different types of cantilever beams incorporating PLZT using 'lift-off' process and anisotropic etching of silicon in EDP. Hence, the proposed technique can be advantageously utilized to fabricate PLZT-based MEMS devices.

\section{Acknowledgements}

This work was carried out under a Sponsored Research Project of Defence Research and Development Organisation (DRDO), Government of India. The authors would like to thank Dr Balakrishnan, Solid State Physics Laboratory, New Delhi for providing the facility of IV measurements.

\section{References}

Baborowski J, Muralt P, Ledermann N, Hiboux S 2000 Etching of $\mathrm{RuO}_{2}$ and Pt thin films with ECR/RF reactor. Vacuum 56: 51-56

Ferguson A T, Li L, Nagaraj V T, Balachandran B, Piekarshki B, DeVoe D L 2005 Modelling and design of composite free-free beam piezoelectric resonators. Sens. Actuat. A118: 63-69

Filhol F, Defay E, Divoux C, Zinck C, Delaye M T 2005 Resonant micro-mirror excited by a thin-film piezoelectric actuator for fast optical beam scanning. Sens. Actuat. A123-124: 483-489

Hong E, Krishnaswamy S V, Freidhoff C B, McKinstry S T 2005 Micromachined piezoelectric diaphragms actuated by ring shaped interdigited transducer electrodes. Sens. Actuat. A119: $520-526$

Johnson L, Gupta A K, Ghafoor A, Akin D, Bashir R 2006 Characterization of vaccinia virus particles using microscale silicon cantilever resonators and atomic force microscopy. Sens. Actuat. B115: 189-197

Lee H C, Park J H, Park J Y, Nam H J, Bu J U 2005 Design, fabrication and RF performances of two different types of piezoelectrically actuated Ohmic MEMS switches. J. Micromech. Microeng. 15: 2098-2104 
Lee J H, Yoon K H, Hwang K S, Park J, Ahn S, Kim T S 2004 Label free novel electrical detection using micromachined PZT monolithic thin film cantilever for the detection of C-reactive protein. Biosens. Bioelectron. 20: 269-275

Maissel L I, Glang R (eds.) (1970) Handbook of Thin Film Technology. (New York: McGraw-Hill Book Company) Ch 4

Muralt P 2000 Ferroelectric thin films for micro-sensors and actuators: a review. J. Micromech. Microeng. 10: 136-146

Park C H, Son Y G, Won M S 2005 Microstructure and ferroelectric properties of RF magnetron sputtering derived PZT thin films deposited on interlayer $\left(\mathrm{PbO} / \mathrm{TiO}_{2}\right)$. Microchem. J. 80: 201-206

Singh R, Chandra S, Sharma S, Tripathi A K, Goel T C 2004 Sol-gel derived La modified PZT thin films; structure and properties. IEEE Tran. Dielect. Elect. Insul. 11(2): 264-270

Singh R, Singh N, Gupta P K, Rashmi Sood K N, Kishore R, Bahadur H, Goel T C, Chandra S 2005 Compositional and structural analysis of RF sputtered PLZT thin films. Proc. of International Conference on Smart Materials, SmartMat-04, Chiang Mai, Thailand, Dec. 2005 351-354

Singh R, Goel T C, Chandra S 2008 Effect of post-deposition annealing on phase formation and properties of RF magnetron sputtered PLZT thin films. Mater. Res. Bull. 43: 384-393

Sze S M 1988 VLSI Technology, (Singapore: McGraw-Hill) Chapter 5, 197p

Thomas R, Mochizuki Mihara S T, Ishida T 2001 Influence of sputtering and annealing conditions on the structure and ferroelectric properties of $\mathrm{Pb}(\mathrm{Zr}, \mathrm{Ti}) \mathrm{O}_{3}$ thin films prepared by $\mathrm{RF}$ magnetron sputtering. Japan. J. Appl. Phys. 40: 5511-5517

Wang W L, He J L 2005 Comparison of the microstructures and ferroelectric characteristics of sputter deposited PZT films with and without lead or lead oxide for compensation. Ceram. Internat. 31: 461-468

Weng L, Bao X, Crentsil K S 2002 Effect of acetylacetone on the preparation of PZT materials in sol-gel processing. Mat. Sci. Eng. B96: 307-312

Yan T, Jones B E, Rakowski R T, Tudor M J, Beeby S P, White N M 2004 Design and fabrication of thick-film PZT-metallic triple beam resonators. Sens. Actuat. A115: 401-407

Zhang Q Q, Gross S J, Tadigadapa S, Jackson T N, Djuth F T, McKinstry S T 2003 Lead zirconate titanate films for $d_{33}$ mode cantilever actuators. Sens. Actuat. A105: 91-97

Zinck C, Pinceau D, Defay E, Delevoye E, Barbier D 2004 Development and characterization of Membranes actuated by a PZT thin film for MEMS applications. Sens. Actuat. A115: 483-489 